\title{
Rheumatoid Arthritis Related Interstitial Lung Disease: Patterns of High-resolution Computed Tomography
}

Mahesh Gautam ${ }^{1}$, Mah Jabeen Masood ${ }^{2}$, Sadaf Arooj ${ }^{2}$, Mufazzal-e-Haque Mahmud ${ }^{3}$, Muhammad Umer Mukhtar 4

1. Radiology, Nobel Medical College, Biratnagar, NPL 2. Radiology, King Edward Medical University, Lahore, PAK 3. Rheumatology and Immunology, Shaikh Zayed Hospital, Lahore, PAK 4. Medicine, King Edward Medical University, Lahore, PAK

Corresponding author: Muhammad Umer Mukhtar, m.umermukhtar@hotmail.com

\section{Abstract \\ Background and aim}

Rheumatoid arthritis (RA) is a chronic inflammatory systemic disease characterized by bilateral involvement of mostly small joints of hands and feet. There can be various extra-articular manifestations of the disease including lung parenchymal disease. Pulmonary involvement in RA patients leads to increased morbidity and mortality. The overall burden of RA related pulmonary disease is underestimated due to the limitation of resources in underdeveloped countries. High-resolution computed tomography (HRCT) is an important tool used to diagnose different abnormalities in RA related interstitial lung disease (ILD). The objective of the study was to evaluate HRCT findings in patients of RA related ILD and categorize the radiological findings according to clinical findings.

\section{Method}

This descriptive prospective observational study was conducted at Mayo Hospital, Lahore from June 2014 to June 2015. Patients of RA suspected of lung disease after selection underwent HRCT chest on 128-slice Hitachi CT scanner (Hitachi Global, Tokyo, Japan) in the radiology department. Images were reconstructed and evaluated by experienced radiologists. Findings were recorded on a questionnaire. Data was analyzed on SPSS version 21 (IBM Corp, Armonk, US).

\section{Results}

Out of the 54 patients scanned, interlobular septal thickening was the most common finding found in 22 of the patients. Ground-glass opacification was recognized in 21 patients, honeycombing in nine and bronchiectasis in two patients. Regarding zonal predilection of disease pattern, lower zones of lungs were found involved in most of the cases. The disease was found to be bilateral in 15 patients. Based on these

Received 01/14/2020 Review began 01/25/2020 Review ended 01/31/2020 Published 02/04/2020

(c) Copyright 2020 Gautam et al. This is an open access article distributed under the terms of the Creative Commons Attribution License CC-BY 4.0., which permits unrestricted use, distribution, and reproduction in any medium, provided the original author and source are credited. findings, usual interstitial pneumonitis (UIP) was diagnosed in six patients and non-specific interstitial pneumonitis (NSIP) in 14 others.

\section{Conclusion}

This study concluded that HRCT images are very useful in diagnosing interstitial lung disease related to rheumatoid arthritis.

Categories: Radiology, Allergy/Immunology, Rheumatology

Keywords: rheumatoid arthritis, interstitial lung disease, hrct

\section{Introduction}

Rheumatoid arthritis (RA) is a chronic inflammatory systemic disease exhibiting clinical signs and symptoms of predominantly joint disease [1-3]. This disease is characterized by symmetrical bilateral involvement of mostly small joints of hand and feet; however as it leads to chronic synovitis, all joints may be involved [4-5]. There can be various extra-articular manifestations (EAM) of the disease e.g. upper airway, lower airway, pleural, vascular and lung parenchymal disease, etc. [6-8]. The overall burden of RA related pulmonary disease is underestimated due to the limitation of resources in underdeveloped countries [9]. Prevalence of interstitial lung disease (ILD) was found to be $97.9 \%$ per 100000 with more of the secondary ILDs than primary ILD. is around 19-44\% [10]. Pulmonary involvement seen in RA patients has high clinical significance as it leads to increased morbidity and mortality [11]. The most important characteristic of RA related pulmonary disease is that almost all anatomical parts of the lung are prone to RA related tissue injury [12]. The overall risk of having ILD in RA patients is $19.2 \%$ as compared to the risk of having ILD in the common population [13]. ILD is a spectrum of pulmonary diseases that involve all parts of pulmonary bronchovascular units, including alveolar epithelium, capillary endothelium, alveoli, perivascular 


\section{Cureus}

connective tissue, and perilymphatic tissues. RA is only second to systemic sclerosis as far as the incidence of ILD in connective tissue disorders is concerned [14]. The natural history of ILD is not very well defined in patients. Complications may arise themself or secondary to immunosuppressive drug treatment. Highresolution computed tomography (HRCT), that emerged during the past decade, is an important tool to diagnose the different abnormalities in RA related ILD.

\section{Materials And Methods}

From June 2014 to June 2015, 54 patients were selected from the outpatient department of Mayo Hospital, Lahore, with RA related pulmonary disease, according to American College of Radiology (ACR) criteria 2010 [15]. The complete history was taken, and patients with co-morbidities like pulmonary tuberculosis, chronic obstructive pulmonary disease (COPD), and lung masses were excluded after evaluating chest X-rays. HRCT chest was performed using a multislice multidetector scanner. Axial images were acquired in a supine position, taking complete deep inspiration. Images were taken using a $0.5 \mathrm{~m}$ slice thickness with at least 1 $\mathrm{cm}$ slice interval. Image reconstruction was done using a bone algorithm.

\section{Results}

Altogether 54 cases were studied to complete the sample size of the project. Out of the 54 patients, 18 (33.33\%) were male, while 36 (66.67\%) were female. The mean age of the patient was $44.17 \pm 11.315$ years, with the minimum age being 15 years and the maximum age being 65 years. Patients had a variable presentation, and the commonest presentation to the hospital was exertional dyspnea (Table 1).

\begin{tabular}{|c|c|c|}
\hline Symptoms & Present & Duration in months \\
\hline Cough & $7(13 \%)$ & 3-6 months \\
\hline Exertional dyspnea & $20(37 \%)$ & 1-3 months \\
\hline Wheezing & 0 & 0 \\
\hline Phlegm & $3(5.6 \%)$ & 1 month \\
\hline
\end{tabular}

\section{TABLE 1: Frequency distribution of the respiratory symptoms}

Regarding the findings of HRCT, interlobular septal thickening was the most common finding, present in 22 (40.7\%) patients. Similarly, ground-glass opacity (GGO) was present in 21 (38.9\%) patients, while nine (16.7\%) patients had honeycombing (Table 2).

\begin{tabular}{|l|l|}
\hline HRCT Findings & Frequency $\%$ \\
\hline Ground-glass attenuation & $21(38.9 \%)$ \\
\hline Honeycombing & $9(16.7 \%)$ \\
Interlobular septal thickening & $21(38.9 \%)$ \\
Nodule & 0 \\
Air trapping & $1(1.9 \%)$ \\
Bronchiectasis & $1(1.9 \%)$ \\
Traction bronchiectasis & $15(27.8 \%)$ \\
Reticular shadowing & $22(40.7 \%)$ \\
Mosaic perfusion & $2(3.7 \%)$ \\
Architectural distortion & $3(5.6 \%)$ \\
\hline
\end{tabular}

TABLE 2: Descriptive statistics of the patients with early rheumatoid arthritis using HRCT

HRCT - high-resolution computed tomography 


\section{Cureus}

Bronchiectasis was present in two (3.7\%) patients, whereas traction bronchiectasis was present in 17 (31.5\%). Air trapping was present in one (1.9\%), mosaic perfusion in two (3.7\%), and architectural distortion in three (5.6\%) patients. GGO, interlobular septal thickening and reticular shadowing, honeycombing, air trapping, mosaic perfusion, and air trapping were found to involve both the lungs. Fifteen (27.8\%) patients had bilateral symmetrical traction bronchiectasis, whereas one (1.9\%) patient had traction bronchiectasis involving right lung and one (1.9\%) patient had traction bronchiectasis involving left lung only (Table 3$)$. Similarly, one (1.9\%) had unilateral bronchiectasis involving the right lung, and one (1.9\%) patient had bronchiectasis involving the left lung.

\begin{tabular}{|c|c|c|c|}
\hline Findings & Unilateral right lung involvement & Unilateral left lung involvement & Bilateral involvement \\
\hline Ground-glass attenuation & 0 & 0 & $21(38.9 \%)$ \\
\hline Honeycombing & 0 & 0 & $9(16.7 \%)$ \\
\hline Interlobular septal thickening & 0 & 0 & $22(40.7 \%)$ \\
\hline Nodule & 0 & 0 & 0 \\
\hline Air trapping & 0 & 0 & $1(1.9 \%)$ \\
\hline Bronchiectasis & $1(1.9 \%)$ & $1(1.9 \%)$ & 0 \\
\hline Traction bronchiectasis & $1(1.9 \%)$ & $1(1.9 \%)$ & $15(27.8 \%)$ \\
\hline Reticular shadowing & 0 & 0 & $22(40.7 \%)$ \\
\hline Alr space opacity & 0 & 0 & 0 \\
\hline Emphysema & 0 & 0 & 0 \\
\hline Cysts & 0 & 0 & 0 \\
\hline Tree-in-bud appearance & 0 & 0 & 0 \\
\hline Crazy-paving appearance & 0 & 0 & 0 \\
\hline Mosaic perfusion & 0 & $2(3.7 \%)$ & 0 \\
\hline Architectural distortion & 0 & $3(5.6 \%)$ & 0 \\
\hline Thickening of bronchovascular bundle & 0 & 0 & 0 \\
\hline
\end{tabular}

TABLE 3: Descriptive statistics of the HRCT findings in unilateral and bilateral involvement of the right and left lung

HRCT- high-resolution computed tomography

Regarding the zone involvement, the lower zone was found to be more frequently involved (Table 4). GGO was found to involve lower zone in 14 (25.9\%) patients, one (1.9\%) patient had involvement of mid zone, five (9.3\%) patients had involvement of the middle and lower zone and one (1.9\%) patient had involvement of all three zones, i.e., upper, mid and lower. Honeycombing was present in the lower zone in six (11.1\%) patients, two (3.7\%) patients had honeycombing in the middle and lower zone, and one (1.9\%) had honeycombing involving all three zones. Thirteen (24.1\%) patients had interlobular septal thickening involving mid and lower zone, eight (14.8\%) had interlobular septal thickening in the lower zone, and one (1.9\%) had interlobular septal thickening involving all three zones. 


\section{Cureus}

\begin{tabular}{|c|c|c|c|c|c|c|c|c|c|c|}
\hline \multirow{2}{*}{ HRCT finding } & \multicolumn{5}{|c|}{ Right lung } & \multicolumn{5}{|c|}{ Left lung } \\
\hline & upper & mid & lower & $\begin{array}{l}\text { mid and } \\
\text { lower }\end{array}$ & $\begin{array}{l}\text { upper mid and } \\
\text { lower }\end{array}$ & upper & mid & lower & $\begin{array}{l}\text { mid and } \\
\text { lower }\end{array}$ & $\begin{array}{l}\text { upper mid and } \\
\text { lower }\end{array}$ \\
\hline Ground-glass Opacity & 0 & $\begin{array}{l}1 \\
(4.8 \%)\end{array}$ & $\begin{array}{l}14 \\
(66.7 \%)\end{array}$ & $5(23.8 \%)$ & $1(4.8 \%)$ & $\begin{array}{l}1 \\
(4.8 \%)\end{array}$ & $\begin{array}{l}14 \\
(66.7 \%)\end{array}$ & $\begin{array}{l}5 \\
(23.8 \%)\end{array}$ & $1(4.8 \%)$ & \\
\hline Honeycombing & 0 & 0 & $\begin{array}{l}6 \\
(66.7 \%)\end{array}$ & $2(22.2 \%)$ & $1(11.1 \%)$ & 0 & 0 & $\begin{array}{l}6 \\
(66.7 \%)\end{array}$ & $2(22.2 \%)$ & $1(11.1 \%)$ \\
\hline $\begin{array}{l}\text { Interlobular septal } \\
\text { thickening }\end{array}$ & 0 & 0 & $\begin{array}{l}8 \\
(36.0 \%)\end{array}$ & $13(59.0 \%)$ & $1(4.0 \%)$ & 0 & 0 & $\begin{array}{l}8 \\
(36.0 \%)\end{array}$ & $13(59.0 \%)$ & $1(4.0 \%)$ \\
\hline Nodule & 0 & 0 & 0 & 0 & 0 & 0 & 0 & 0 & 0 & 0 \\
\hline Air trapping & 0 & 0 & $\begin{array}{l}1 \\
(100 \%)\end{array}$ & 0 & 0 & 0 & 0 & $\begin{array}{l}1 \\
(100 \%)\end{array}$ & 0 & 0 \\
\hline Bronchiectasis & 0 & 0 & 0 & 0 & $1(100 \%)$ & 0 & 0 & $\begin{array}{l}1 \\
(100 \%)\end{array}$ & 0 & 0 \\
\hline $\begin{array}{l}\text { Traction } \\
\text { bronchiectasis }\end{array}$ & 0 & $\begin{array}{l}1 \\
(6.7 \%)\end{array}$ & $\begin{array}{l}1 \\
(100 \%)\end{array}$ & 0 & 0 & 0 & $1(6.7 \%)$ & $\begin{array}{l}1 \\
(100 \%)\end{array}$ & 0 & 0 \\
\hline Reticular shadowing & 0 & 0 & $\begin{array}{l}16 \\
(68.2 \%)\end{array}$ & $6(27.3 \%)$ & $1(4.5 \%)$ & 0 & 0 & $\begin{array}{l}16 \\
(68.2 \%)\end{array}$ & $6(27.3 \%)$ & $1(4.5 \%)$ \\
\hline
\end{tabular}

TABLE 4: Descriptive statistics of the HRCT findings in term of zone involved among patients with early rheumatoid arthritis

HRCT - high-resolution computed tomography

Based on these patterns of involvement of the lung, usual interstitial pneumonia (UIP) was diagnosed in six (11.1\%) patients (Table 5). Similarly, non-specific interstitial pneumonia (NSIP) was diagnosed in 14 (25.9\%) of the patients. Findings of HRCT that did not fall under any defined category were labeled as others, as were present in five $(9.3 \%)$ patients.

\begin{tabular}{|c|c|c|c|c|}
\hline Diagnosis & Frequency & Percent & Valid percent & Cumulative percent \\
\hline Normal & 29 & 53.7 & 53.7 & 53.7 \\
\hline Usual interstitial pneumonia & 6 & 11.1 & 11.1 & 64.8 \\
\hline NSIP & 14 & 25.9 & 25.9 & 90.7 \\
\hline Others & 5 & 9.3 & 9.3 & 100.0 \\
\hline Total & 54 & 100.0 & 100.0 & \\
\hline
\end{tabular}

TABLE 5: Frequency distribution of the HRCT diagnosis in patients with early rheumatoid arthritis NSIP - non-specific interstitial pneumonia

\section{Discussion}

The present study indicates that females are at increased risk of RA with the statistical odds of (66.67\% vs. 33.3\%). The results of this study are comparable with the study by Gabbay E et al. that demonstrated females to be at an increased risk of RA (69.44\%) [16]. El Khalik KA et al. found that RA was more common in females than in males (79.4\% vs. 20.58\%) [17]. This disparity may be due to bias in the selection of women. The present study provides evidence that RA patients were older individuals of $44.17 \pm 11.315$ years. Gabbay E et al. demonstrated that RA was more commonly found in older patients $51.8 \pm 16.0$ years [16]. Affara NK et al. examined RA patients to be $52.6 \pm 5.1$ years old [18]. The discrepancy in the mean age of the patients in our study may be present due to the small sample size. 


\section{Cureus}

Affara NK et al. examined HRCT abnormalities in their study, i.e., GGO was present in 30\%, air space opacification (AS) was present in 13.3\%, mixed AS/GGO was present in $13.3 \%$, honeycombing in $10 \%$, septal thickening in $26.7 \%$ and traction bronchiectasis in $11.7 \%$ of the subjects [18]. In contrast with these studies, our study reported interlobular septal thickening as the most common HRCT finding, present in 22 (40.7\%) patients and illustrated in Figures 1 and 2.

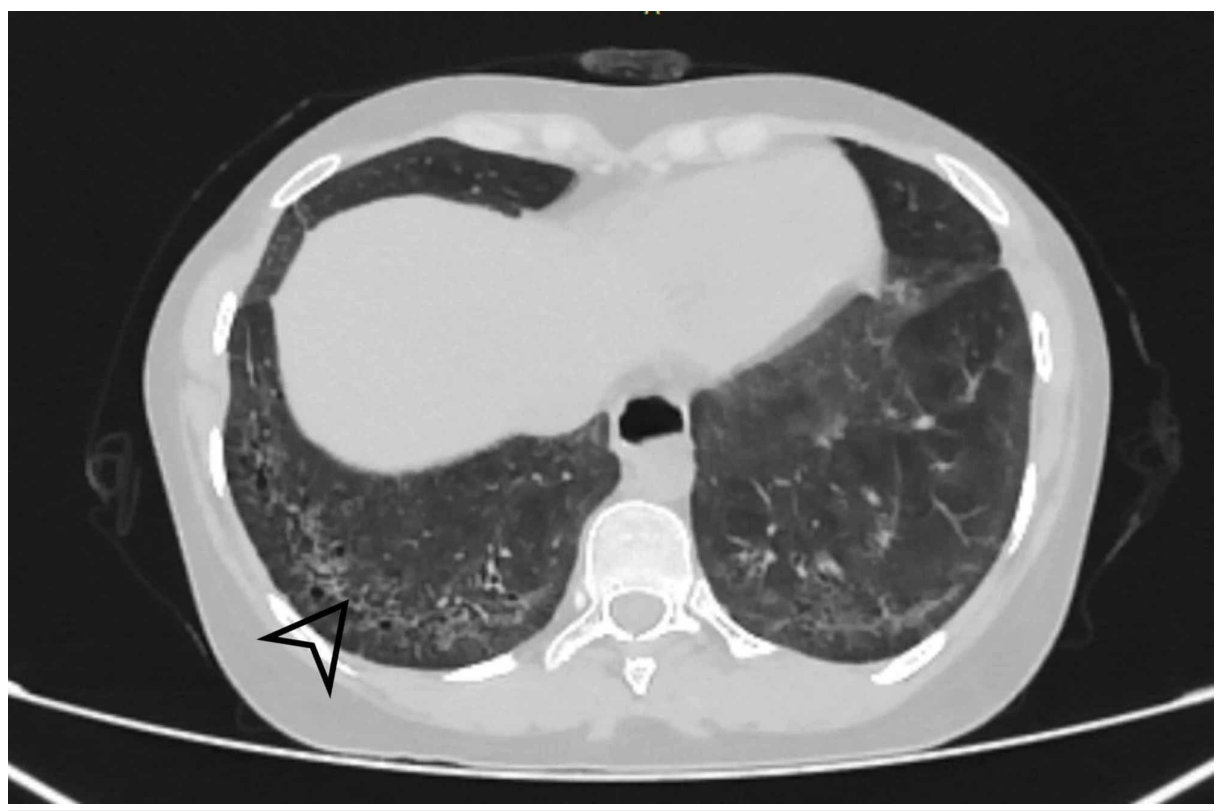

FIGURE 1: Axial section revealing bilateral basal intralobular septal thickening with sparing of subpleural areas

Black arrowhead shows Interlobular septal thickening.

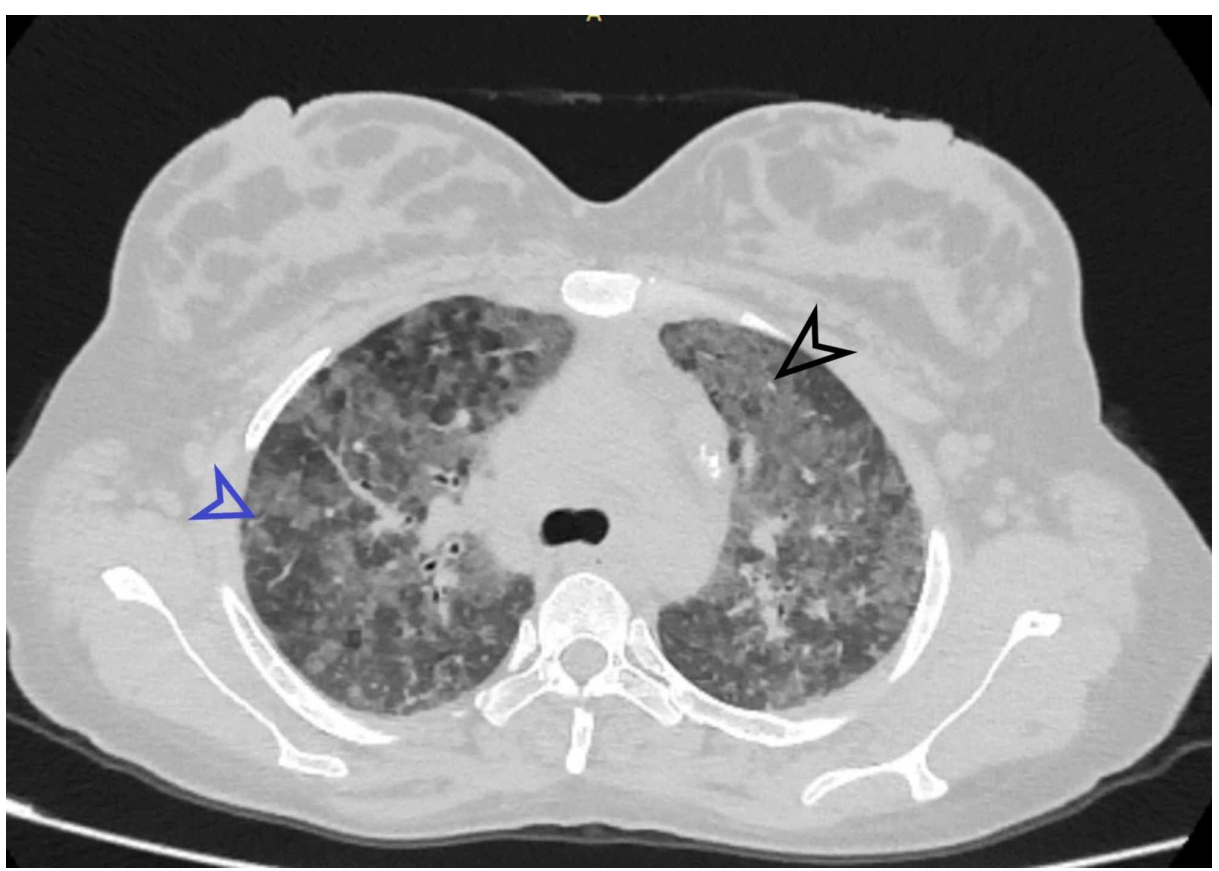

FIGURE 2: Patchy areas of GGO and interlobular septal thickening involving bilateral upper lobes

Black arrowhead indicates the ground-glass opacity (GGO). Blue arrowhead shows interlobular septal thickening. 


\section{Cureus}

Similarly, GGO was present in 21 (38.9\%) patients (Figure 2), nine (16.7\%) patients had honeycombing. Bronchiectasis was present in two (3.7\%), whereas traction bronchiectasis was present in 17 (31.5\%) such as shown in Figure 3. Air trapping was present in one (1.9\%), two (3.7\%) patients had mosaic perfusion, and three (5.6\%) patients had architectural distortion.

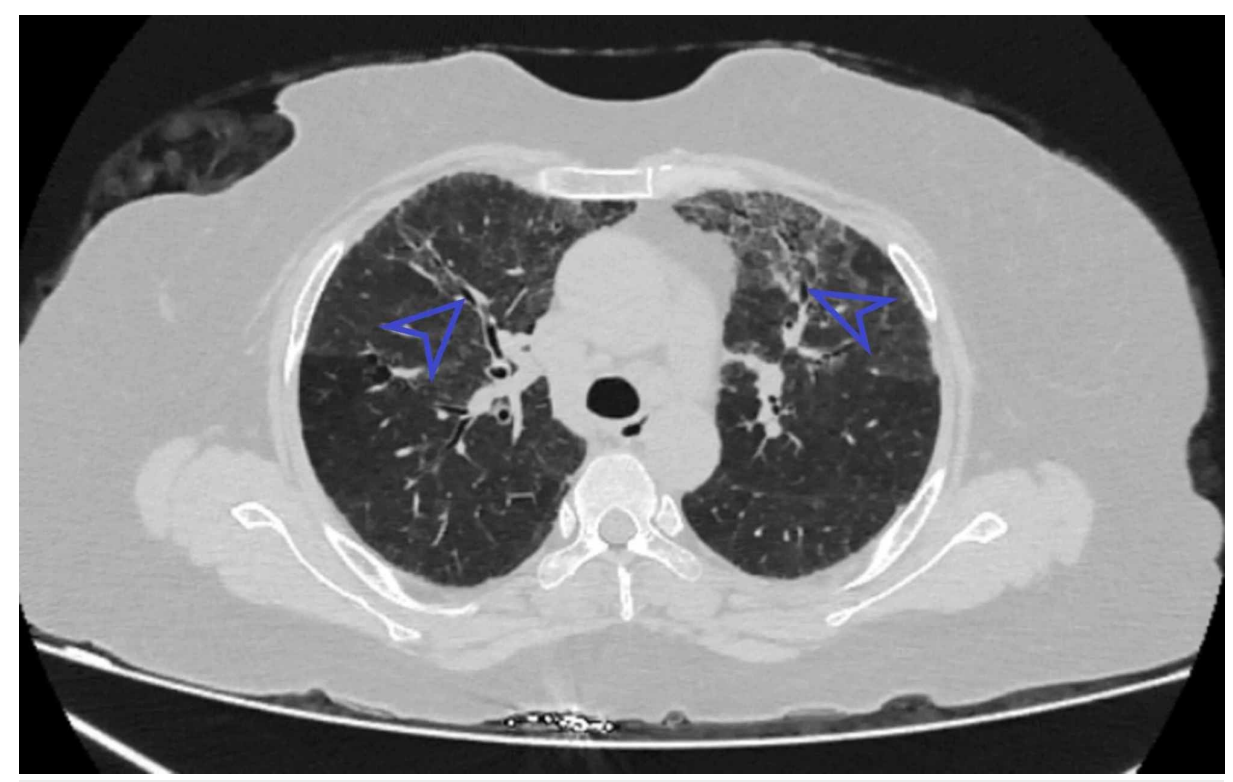

\section{FIGURE 3: Axial section showing bronchiectasis}

Blue arrowhead indicates bronchiectasis.

Metafratzi ZM et al. .used normal healthy individuals as control against known patients of RA [19]. They used a semi-quantitative grading system, which has also been described in the past. The presence and extent of findings on HRCT chest were coded according to lung zones bilaterally, making a total of six zones. Only air trapping was given a score of eight on its presence on paired inspiratory and expiratory images. The control subjects showed minimal findings with scores of less than 3.6. The most common findings were air trapping and bronchiectasis. The abnormalities noticed in patients were equal to a score of 5.2 (moderate in severity) with only air trapping having a score of 14 (maximum severity). Other findings were bronchiectasis, bronchial wall thickening, macro nodules, and GGO.

Chansakul TN, in their study, concluded that traction bronchiectasis and the extent of honeycombing (as our earlier findings illustrated in Figures 4-6) were strongly associated with morbidity and mortality [20]. RA related ILD carried a bad prognosis when they compared HRCT findings to pulmonary function tests. They also completely evaluated patients' intrathoracic noncardiac findings on CT scans in terms of pleural, parenchymal, vascular disease as well as drug-related complications and opportunistic infections. They found that UIP (illustrated in Figure 5) was commoner than NSIP. There was more overlap between NSIP and UIP patterns. 


\section{Cureus}

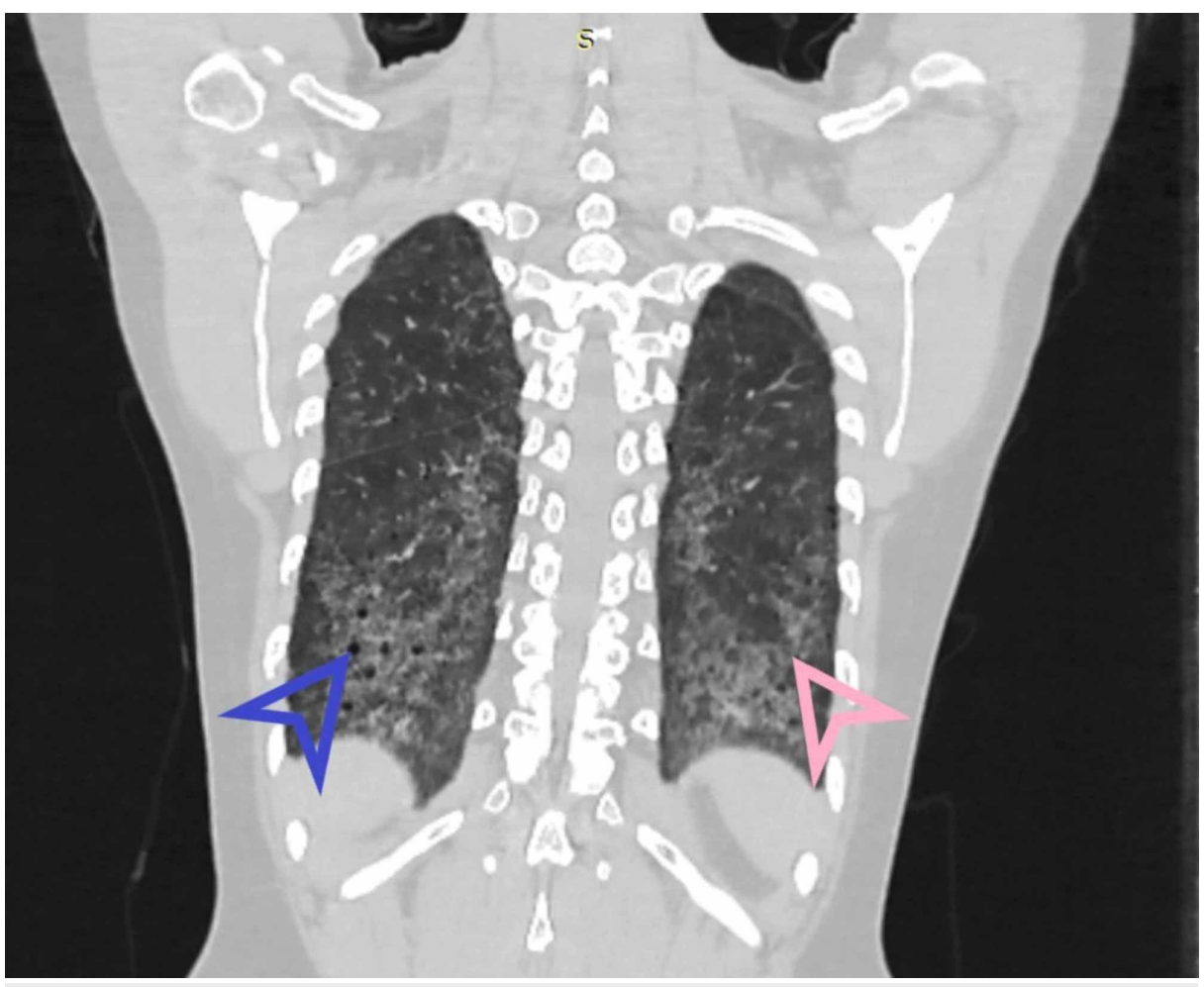

FIGURE 4: Coronal HRCT showing basal predominance of fibrosis and honeycombing in UIP

HRCT - high-resolution computed tomography; UIP - usual interstitial pneumonia

Blue arrowhead indicates honeycombing. Pink arrowhead shows fibrosis.

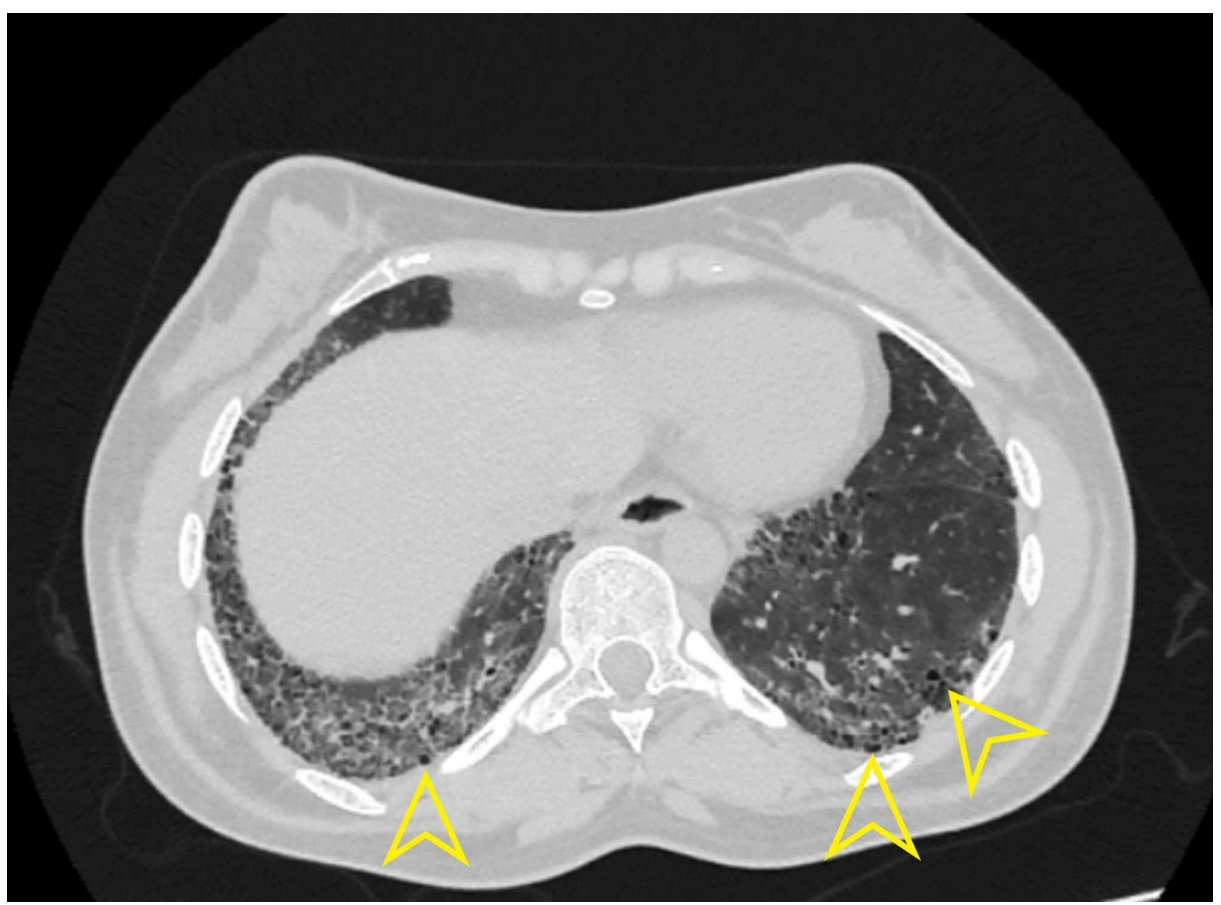

FIGURE 5: Axial section high-resolution computed tomography showing UIP

Yellow arrowhead indicating honeycombing in usual interstitial pneumonia (UIP). 


\section{Cureus}

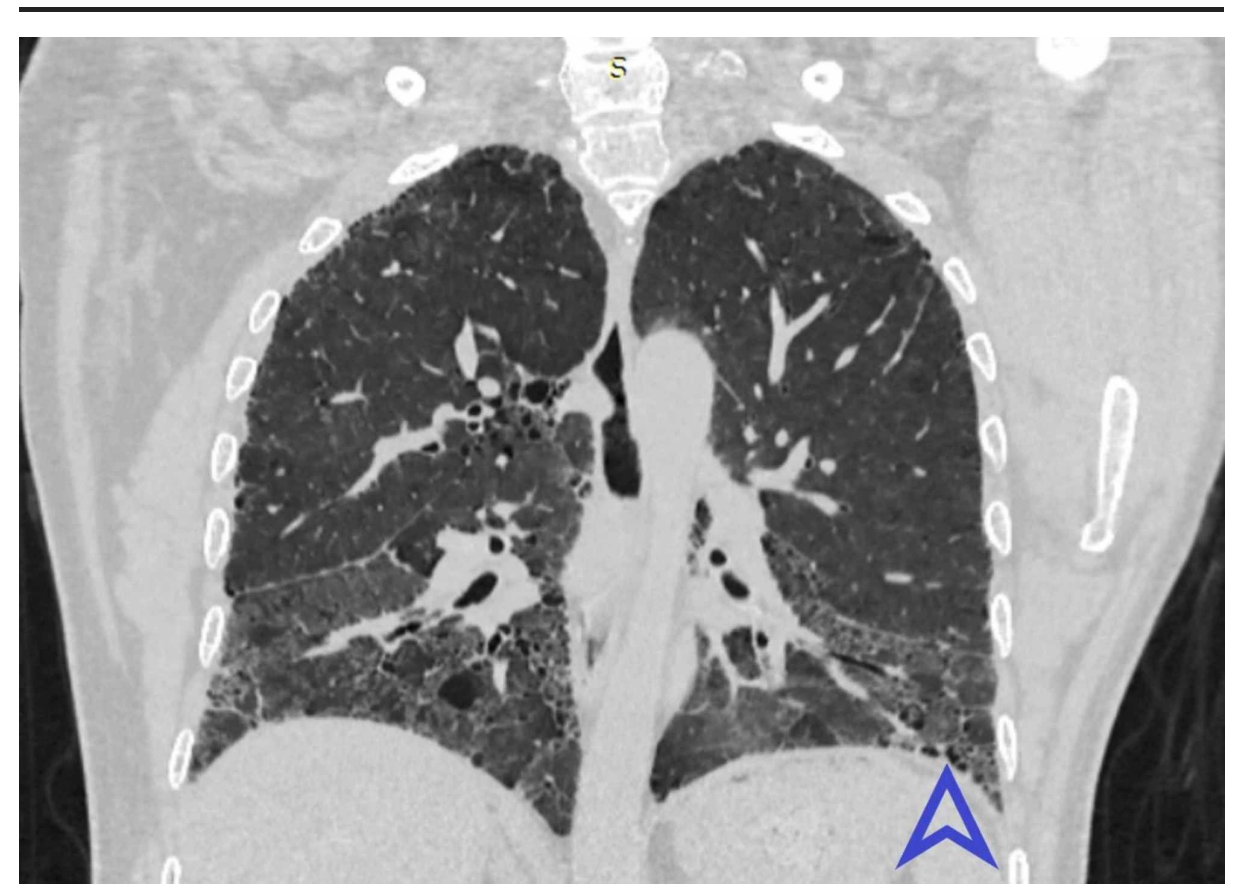

FIGURE 6: Coronal view HRCT shows bilateral symmetrical fibrosis in lower lobes

HRCT - high-resolution computed tomography

Blue arrowhead shows honeycombing.

\section{Conclusions}

Multiple pulmonary manifestations of RA are well known. Investigation for ILD is mandatory for evaluating the clinical progression of RA. HRCT detects subtle abnormalities in RA patients even without respiratory symptoms. Thus, HRCT is the investigation of choice to delineate in detail the bronchovascular involvement and disease patterns of the lungs in patients of RA.

\section{Additional Information}

\section{Disclosures}

Human subjects: Consent was obtained by all participants in this study. Institutional Review Board of King Edward Medical University, Lahore issued approval 476/RC/KEMU. The Synopsis of Dr. Mahesh Gautam, PG Trainee - MD Diagnostic Radiology, Department of Radiology, King Edward Medical University was presented before the Institutional Review Board for ethical approval. The committee after discussion approved the synopsis and found it appropriate and awarded the study ethical approval. Animal subjects: All authors have confirmed that this study did not involve animal subjects or tissue. Conflicts of interest: In compliance with the ICMJE uniform disclosure form, all authors declare the following: Payment/services info: All authors have declared that no financial support was received from any organization for the submitted work. Financial relationships: All authors have declared that they have no financial relationships at present or within the previous three years with any organizations that might have an interest in the submitted work. Other relationships: All authors have declared that there are no other relationships or activities that could appear to have influenced the submitted work.

\section{References}

1. Akhter E, Bilal S, Kiani A, Haque U: Prevalence of arthritis in India and Pakistan: a review . Rheumatol Int. 2011, 31:849-855. 10.1007/s00296-011-1820-3

2. Johnson C: Recent advances in the pathogenesis, prediction and management of rheumatoid arthritis associated with interstitial lung disease. Curr Opin Rheumatol. 2017, 29:254-259. 10.1097/BOR.0000000000000380

3. Shaw M, Collins BF, Ho LA, Raghu G: Rheumatoid arthritis-associated lung disease . Eur Respir Rev. 2015, 24:1-16. 10.1183/09059180.00008014

4. Bongartz T, Nannini C, Medina-Velasquez YF, et al.: Incidence and mortality of interstitial lung disease in rheumatoid arthritis: a population-based study. Arthritis Rheum. 2010, 62:1583-1591. 10.1002/art.27405

5. Norton S, Koduri G, Nikiphorou E, Dixey J, Williams P, Young A: A study of baseline prevalence and 
cumulative incidence of comorbidity and extra-articular manifestations in RA and their impact on outcome. Rheumatology. 2013, 52:99-110. 10.1093/rheumatology/kes262

6. Hamblin MJ, Horton MR: Rheumatoid arthritis associated interstitial lung disease: diagnostic dilemma . Pulm Med. 2011, 872120. 10.1155/2011/872120

7. Pappas DA, Giles JT, Connors G, Lechtzin N, Bathon JM, Danoff SK: Research article Respiratory symptoms and disease characteristics as predictors of pulmonary function abnormalities in patients with rheumatoid arthritis: an observational cohort study. Arthritis Res Ther. 2010 , 12:R104. 10.1186/ar3037

8. Dokwal CP: Pulmonary manifestations of collagen vascular disease. Pulse. 2010, 4:16-21. 10.3329/pulse.v4i1.6958

9. Yunt ZX, Solomon J: Lung disease in rheumatoid arthritis. Rheum Dis Clin. 2015, 41:225-236.

10. Duchemann B, Annesi-Maesano I, Jacobe de Naurois C, et al.: Prevalence and incidence of interstitial lung diseases in a multi-ethnic county of Greater Paris. Eur Respir J. 2017, 50:1602419. 10.1183/13993003.024192016

11. Assayag D, Elicker BM, Urbania TH, et al.: Rheumatoid arthritis-associated interstitial lung disease: radiologic identification of usual interstitial pneumonia pattern. Radiology. 2014, 270:583-588. 10.1148/radiol.13130187

12. Zou YQ, YS, Ding XN, Ying ZH: The clinical significance of HRCT in evaluation of patients with rheumatoid arthritis-associated interstitial lung disease: a report from China. Rheumatol Int. 2012, 32:669-673. 10.1007/s00296-010-1665-1

13. Salaffi F, Carotti M,Di Carlo M,Tardella M, Giovagnoni A: High-resolution computed tomography of the lung in patients with rheumatoid arthritis: prevalence of interstitial lung disease involvement and determinants of abnormalities. Ann Rheum Dis. 2019, 78:350.

14. Bhattacharya P, Ghosh S, Sengupta S, Dasgupta A, Ghosh, K, Ghosh B: Clinicoradiological profile of interstitial lung disease in rheumatoid arthritis. Asian J Med Sci. 2018, 10:66-71. 10.3126/ajms.v10i1.20123

15. Aletaha D, Neogi T, Silman AJ, et al.: 2010 rheumatoid arthritis classification criteria: an American College of Rheumatology/European League Against Rheumatism collaborative initiative. Arthritis Rheumatol. 2010, 62:2569-2581. 10.1002/art.27584

16. Gabbay E, Tarala R, Will R, Carroll G, Adler B, Cameron D, Lake FR: Interstitial lung disease in recent onset rheumatoid arthritis. Am J Respir Crit Care Med. 1997, 156:528-535. 10.1164/ajrccm.156.2.9609016

17. Abd el-khalik KA, El-Sayed ZA, Faheem MS, Fouda E, Abdurrahman L, Abd El-Ghany S: High resolution computed tomography and pulmonary function tests in childhood systemic lupus erythematosus and juvenile rheumatoid arthritis. Egypt J Pediatr Allergy Immunol. 2004, 2:8-15.

18. Affara NK, Refaat AM, Elgawish MH, Zakaria MA, Dashti KA: .High-resolution CT and pulmonary function tests in rheumatoid arthritis patients with subclinical interstitial lung disease in Kuwait. Egypt Rheumatol. 2015, 38:77-83. 10.1016/j.ejr.2015.06.003

19. Metafratzi ZM, Georgiadis AN, Ioannidou CV, et al.: Pulmonary involvement in patients with early rheumatoid arthritis. Scand J Rheumatol. 2017, 36:338-344. 10.1080/03009740701393957

20. Chansakul T, Dellaripa PF, Doylec TJ, Madan R: Intra-thoracic rheumatoid arthritis: Imaging spectrum of typical findings and treatment related complications. Eur J Radiol. 2015, 84:1981-1991. 10.1016/j.ejrad.2015.07.008 